\title{
CARDIAC NORADRENALINE STORES
}

\author{
BY \\ G. FAWAZ AND J. SIMAAN \\ From the Department of Pharmacology, School of Medicine, American University of \\ Beirut, Beirut, Lebanon
}

(Received November 27, 1962)

\begin{abstract}
The effects of single doses of reserpine or of guanethidine in increasing the heart rate of the dog heart-lung preparation have been studied. Compared with reserpine, guanethidine increased heart rate more and more rapidly, and the increase lasted longer. When the effects of reserpine had subsided, guanethidine now caused a similar rate of change and maximum increase in heart rate, but recovery was quicker. Guanethidine given alone caused ress release of noradrenaline in the right atrium than did reserpine alone, but both drugs together caused greater release than did either alone. Thus liberation of noradrenaline in the right atrium was unrelated to the effectiveness of either drug to increase heart rate. Guanethidine and reserpine did not increase the heart rate of heart-lung preparations from dogs which had received reserpine for 2 days and which contained no noradrenaline. Guanethidine had similar actions on the heart rate of preparations either given a slow intravenous infusion of noradrenaline or a single dose of reserpine. Treatment of a normal heart-lung preparation with noradrenaline increased the atrial noradrenaline content, but subsequent addition of reserpine or of guanethidine changed heart rate in the same manner as for preparations not given noradrenaline. Treatment with reserpine increased the heart's sensitivity to noradrenaline without changing initial heart rate. These results are discussed in relation to the idea that there may be more than one noradrenaline compartment in the heart.
\end{abstract}

The observation of Bertler, Carlsson \& Rosengren (1956) that intravenous injection of reserpine into rabbits reduced the noradrenaline content of the heart almost to zero, and the finding of Carlsson, Rosengren, Bertler \& Nilsson (1957) that tyramine had little or no pressor effect after treatment of cats with reserpine, was followed by the demonstration by Burn \& Rand (1958) that the pressor action of tyramine in spinal cats with reserpine may be restored, at least in part, after an infusion of noradrenaline. We have studied the acute effects of reserpine and guanethidine, singly and together, on the heart rate of the dog heart-lung preparation. We have also studied the effects of infusions of noradrenaline on the noradrenaline content of the right atrium in normal preparations as well as those from dogs treated with reserpine, and the results of subsequent treatment with reserpine or guanethidine.

During our work, Gaffney (1961) and Krayer, Alper \& Paasonen (1962) have reported the acute effects of guanethidine on the dog isolated heart, and Krayer $e t$ al. (1962), Crout, Muskus \& Trendelenburg (1962) and Fawaz (1963) have reviewed the subject. 


\section{METHODS}

The experimental dogs were anaesthetized with sodium pentobarbitone ( 30 to $40 \mathrm{mg} / \mathrm{kg}$ ). Blood-donor dogs were anaesthetized with chloroform. More than 100 conventional Starling heart-lung preparations were made. The conditions employed were: total volume of blood about 1 l., temperature $38^{\circ} \mathrm{C}$, outflow resistance-pressure maintained at $68 \mathrm{~mm} \mathrm{Hg}$, arterial blood pressure between 100 and $120 \mathrm{~mm} \mathrm{Hg}$, and systemic output at the start of the experiments between 600 and $800 \mathrm{ml} . / \mathrm{min}$. The lungs were ventilated with pure oxygen and, if hypoxaemia occurred, oxygen was introduced into the venous reservoir as described by Fawaz \& Tutunji (1957). The heart rate was counted using a stop-watch over a period of $30 \mathrm{sec}$ every $5 \mathrm{~min}$. In the first twenty experiments the counted heart rate was identical to that measured from an electrocardiograph.

Reserpine base was dissolved in $20 \%$ ascorbic acid. Reserpine $(3 \mathrm{mg}$ ) and guanethidine (Ismelin, $10 \mathrm{mg}$ ) were put into the venous reservoir over periods of 3 and 5 min respectively. Unless otherwise stated, the preparations were allowed to run for about $3 \mathrm{hr}$ after administration of a drug, and then the right atrium was excised for the estimation of noradrenaline. In control experiments, the preparation was allowed to run for the same length of time. Treatment with reserpine consisted of intraperitoneal injections of $0.5 \mathrm{mg} / \mathrm{kg}, 48 \mathrm{hr}$ and $24 \mathrm{hr}$ before the experiment; animals thus treated usually required less pentobarbitone for anaesthesia.

The method of estimation of noradrenaline was that of von Euler (1957) as used by Paasonen \& Krayer (1958) with minor modifications. The whole right atrium was excised, freed from blood and frozen in liquid air. It was then dried with blotting paper, weighed quickly and ground to a fine powder in a mortar previously cooled with liquid air. The powder was then transferred to $5 \%$ trichloracetic acid solution, using $5 \mathrm{ml}$. of solution per $\mathrm{g}$ of heart, and allowed to stand for $1 \mathrm{hr}$ at room temperature with occasional shaking. After centrifugation, the supernatant fluid was filtered and treated with $10 \mathrm{mg}$ of ascorbic acid and freshly prepared $20 \%$ aluminium sulphate solution $(1 \mathrm{ml} . / 100 \mathrm{ml}$. of filtrate). The solution was then brought to $p \mathrm{H} 7.5$ with $2 \%$ sodium hydroxide solution. The gelatinous precipitate was separated by centrifugation, washed with $0.9 \%$ saline and again centrifuged. After decantation the precipitate was dissolved by adding a few drops of $10 \mathrm{~N}-\mathrm{H}_{2} \mathrm{SO}_{4}$ and the solution carefully brought to $\mathrm{pH} 3$ with $10 \%$ sodium hydroxide solution. Four volumes of a 1:1 mixture of acetone and $95 \%$ ethanol were then added with stirring, and the tubes left closed in a refrigerator overnight. After centrifugation, the supernatant fluid was quickly evaporated to 0.5 to $1 \mathrm{ml}$. at a temperature not exceeding $8^{\circ} \mathrm{C}$, by a modification for small volumes of the ice-desiccator method of Jantzen \& Schmalfuss (1929). The final volume $(p \mathrm{H}=3)$ was adjusted with $0.9 \%$ saline so that $1 \mathrm{ml}$. corresponded to $1 \mathrm{~g}$ of atrial tissue. Bioassay was performed with cats anaesthetized with chloralose and treated with heparin, but usually without artificial ventilation. The cats had received atropine $(1 \mathrm{mg} / \mathrm{kg})$ subcutaneously and ergotamine $(0.1 \mathrm{mg} / \mathrm{kg})$ intramuscularly. The sensitivity of the cat to the pressor action of noradrenaline was tested before the assay. Usually, four atria were treated simultaneously and, with each run, a known amount of noradrenaline was added to a portion of the trichloracetic acid filtrate. The recovery was always between 95 and $100 \%$.

\section{RESULTS}

The effect of reserpine. Reserpine $(3 \mathrm{mg}$ ) was added to the venous reservoir during 3 min. Krayer \& Fuentes (1958) reported that this dose produced a maximum increase in heart rate. Fig. 1 (continuous line) shows the mean results from twenty experiments. A maximum heart rate of about 200 beats $/ \mathrm{min}$ was reached within $20 \mathrm{~min}$ and the rate returned to the control value in less than $2 \mathrm{hr}$.

The effect of guanethidine. Guanethidine (10 $\mathrm{mg}$ over $5 \mathrm{~min})$ gave a maximum increase in heart rate; the results of Krayer et al. (1962) indicate that $30 \mathrm{mg}$ of 


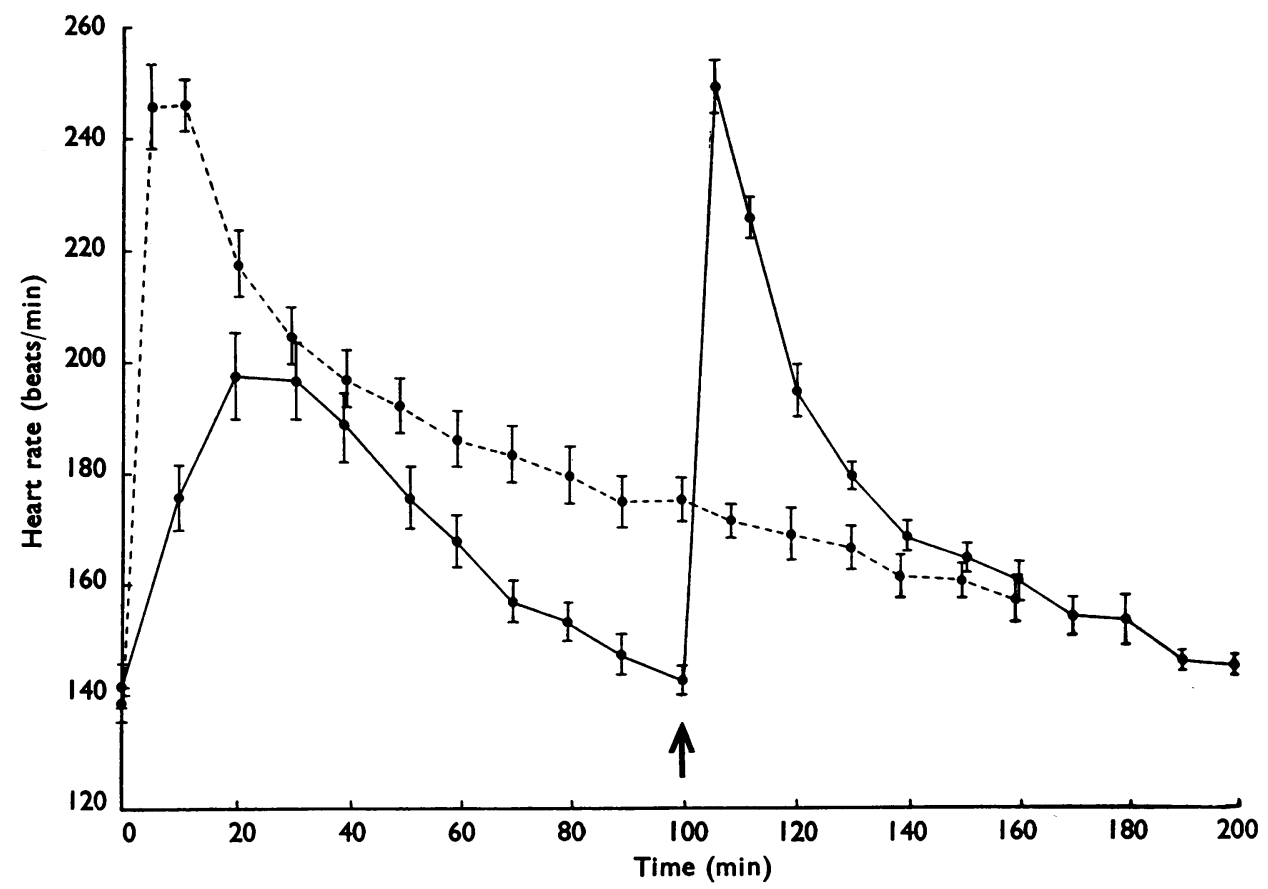

Fig. 1. Effects upon heart rate of reserpine and guanethidine added (at zero time) to the venous reservoir of the heart-lung preparation. Continuous line: response to reserpine $(3 \mathrm{mg})$ followed, at arrow, by guanethidine $(10 \mathrm{mg})$; mean results from twenty experiments. Broken line: response to guanethidine $(10 \mathrm{mg})$ alone; mean results from fifteen experiments. The vertical lines indicate standard errors of the means.

guanethidine would have been no more effective. Fig. 1 (broken line) shows that the maximum heart rate of about 250 beats/min was reached within $5 \mathrm{~min}$ or at the end of the infusion. In contrast to the experiments with reserpine, the heart rate did not return to the control value for at least $3 \mathrm{hr}$.

The effect of reserpine followed by guanethidine. When guanethidine was added after the chronotropic effect of reserpine had subsided (Fig. 1, continuous line, at arrow) the maximum heart rate was almost the same as that without prior addition of reserpine (Fig. 1, broken line). The curve for guanethidine after addition of reserpine descended more steeply and the chronotropic effect subsided in less than $2 \mathrm{hr}$. The area under the curve for guanethidine without reserpine is roughly equal to the total area under the curve for reserpine plus guanethidine.

The effect of infusion of noradrenaline followed by reserpine or guanethidine. First, $480 \mu \mathrm{g}$ of noradrenaline were infused during $30 \mathrm{~min}$. After the heart rate had almost returned to normal, reserpine or guanethidine was administered. Control experiments were run simultaneously, and guanethidine or reserpine was added to these preparations at the same time as to those treated with noradrenaline. Five experiments and five controls were performed. The curves for reserpine and guanethidine did not differ appreciably from those for which no noradrenaline had been given (Figs. 2 and 3). 
(a)

(b)
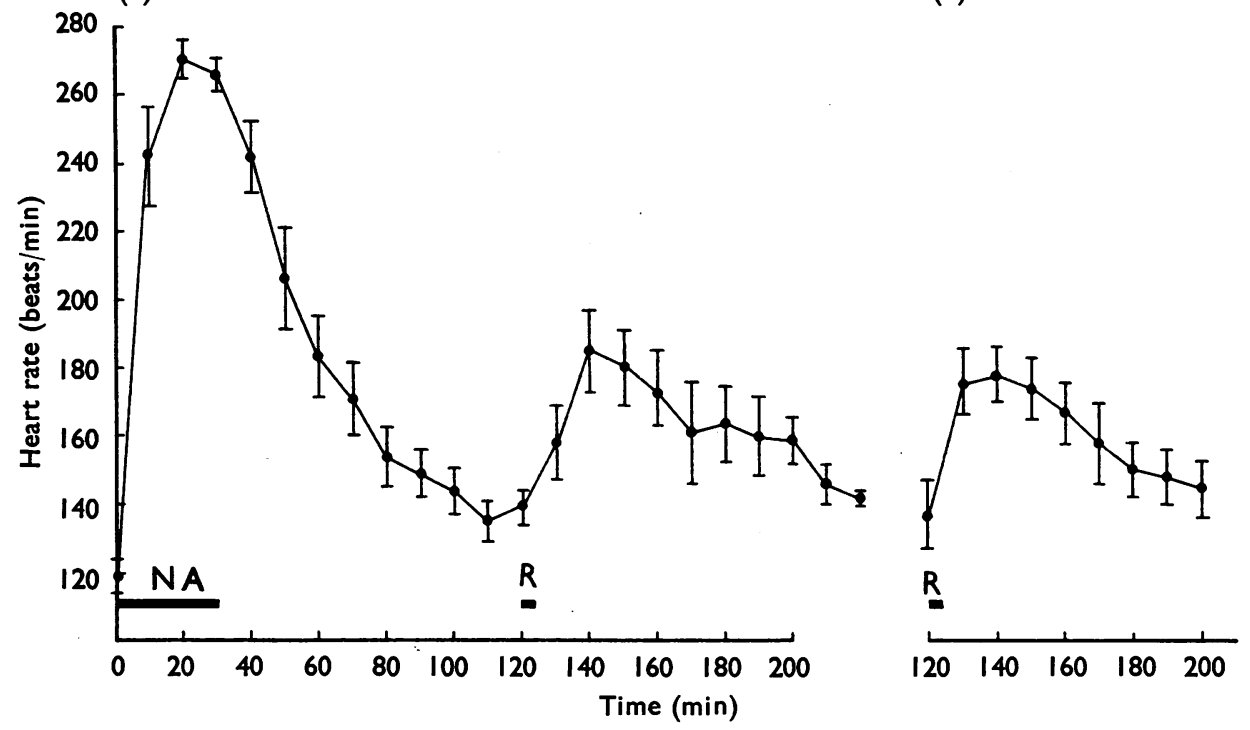

Fig. 2. Changes in heart rate of heart-lung preparation in response to reserpine after treatment with noradrenaline. (a) noradrenaline $(480 \mu \mathrm{g})$ added to venous reservoir over a period of $30 \mathrm{~min}$ at NA, followed by reserpine ( $3 \mathrm{mg}$ ) at $\mathrm{R}$. (b) reserpine $(3 \mathrm{mg}$ ) alone at $\mathrm{R}$. Mean results from five experiments each in $(a)$ and $(b)$. Vertical lines are standard errors of the means.

(a)

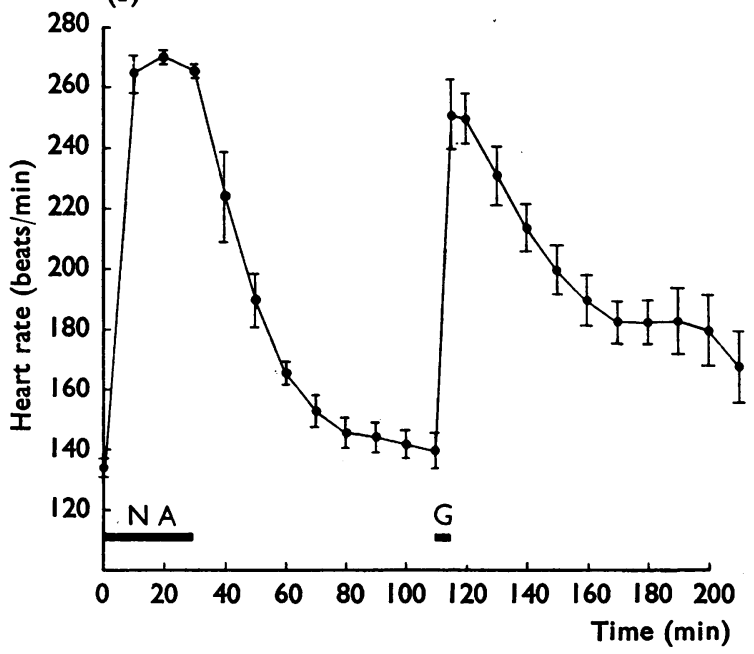

(b)

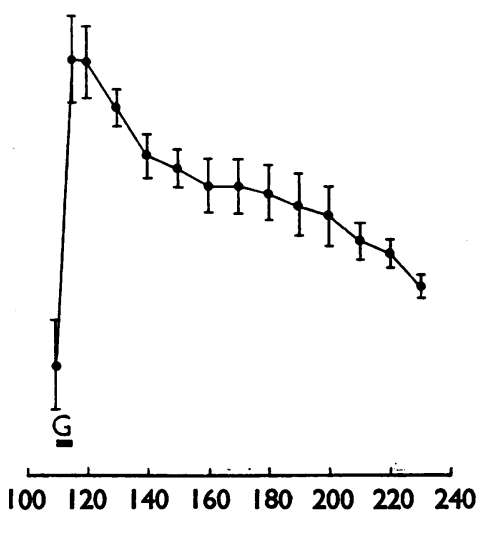

Fig. 3. Changes in heart rate of heart-lung preparation in response to guanethidine after treatment with noradrenaline. (a) noradrenaline $(480 \mu \mathrm{g})$ added to venous reservoir over a period of 30 min at NA, followed by guanethidine $(10 \mathrm{mg})$ at $\mathrm{G}$. (b) guanethidine $(10 \mathrm{mg})$ alone. Mean results from five experiments each in $(a)$ and $(b)$. Vertical lines are standard errors of the means. 


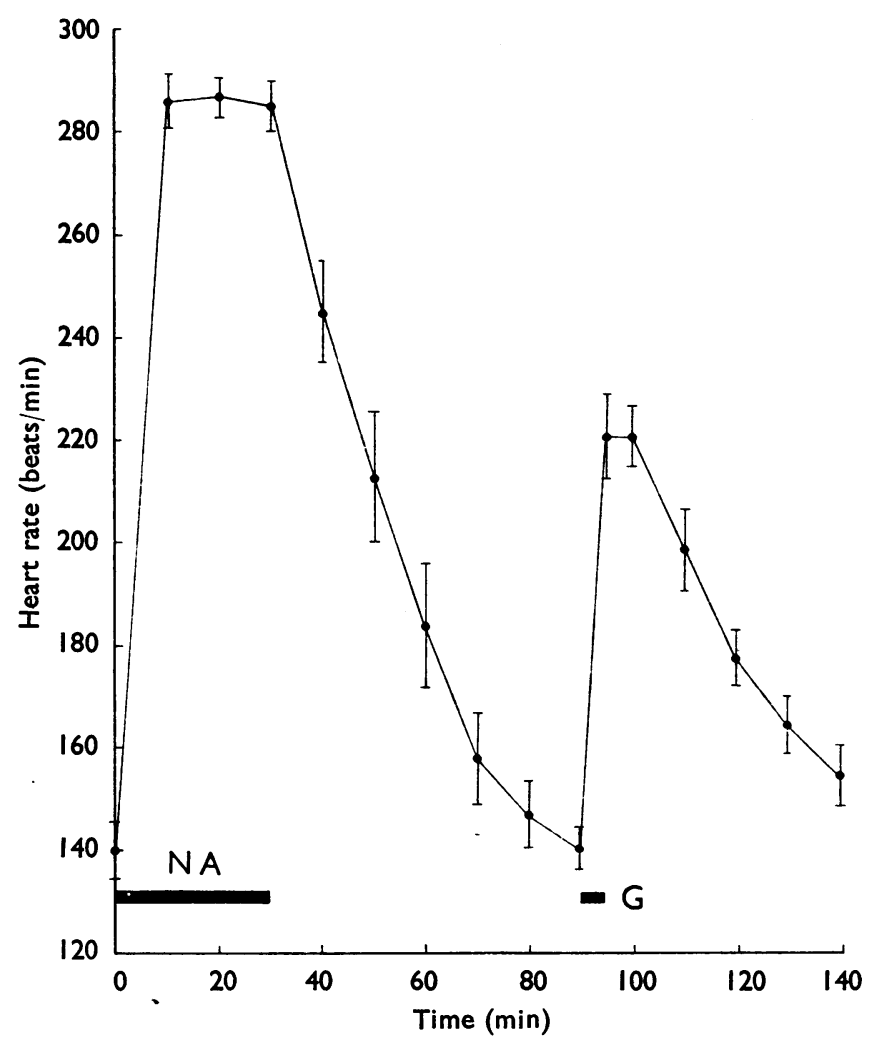

Fig. 4. Effect of noradrenaline infusion followed by guanethidine on the heart rate of heart-lung preparations from dogs treated with reserpine. Noradrenaline $(480 \mu \mathrm{g})$ was added to the venous reservoir over a period of $30 \mathrm{~min}$ at NA, followed by guanethidine $(10 \mathrm{mg})$ at $\mathrm{G}$. Mean results from nine experiments, with standard errors.

The effect of infusion of noradrenaline followed by guanethidine on heart-lung preparations from dogs treated with reserpine. The addition of noradrenaline to the dog heart-lung preparation treated beforehand with reserpine resulted in a greater increase in heart rate than in controls (Fig. 4). After infusion of noradrenaline into the heart-lung preparation from such dogs, guanethidine increased the heart rate with a maximum not much lower than that reached with guanethidine alone. However, the fall was more abrupt and was reminiscent of the curve obtained with the normal preparation (Fig. 1) in which a dose of reserpine was added before guanethidine. In several experiments with dogs treated with reserpine, in which an infusion of noradrenaline was not given, addition of guanethidine caused no increase in heart rate.

The heart rate of preparations from animals treated with reserpine. The average initial heart rate of nine preparations from animals previously treated with reserpine was 139 beats/min (Fig. 4), and was thus not very different from that of preparations not so treated. The average initial heart rate of the fourteen preparations used to study the noradrenaline content after repletion was 136 beats/min. 
TABLE 1

THE CONTENT OF NORADRENALINE IN THE RIGHT ATRIUM OF THE DOG UNDER DIFFERENT EXPERIMENTAL CONDITIONS

Noradrenaline contents are means \pm standard errors

\begin{tabular}{|c|c|c|c|c|}
\hline $\begin{array}{l}\text { Experimental } \\
\text { condition }\end{array}$ & $\begin{array}{l}\text { Number of } \\
\text { experiments }\end{array}$ & Treatment & $\begin{array}{l}\text { Duration of experi- } \\
\text { ment before excision } \\
\text { of atrium }\end{array}$ & $\begin{array}{c}\text { Noradrenaline } \\
\text { content of } \\
\text { atrium }(\mu \mathrm{g} / \mathrm{g})\end{array}$ \\
\hline Heart-lung preparation & 15 & $\begin{array}{l}\text { Reserpine }(3 \mathrm{mg} \text { in } \\
3 \mathrm{~min})\end{array}$ & $3 \mathrm{hr}$ & $0.38 \pm 0.063$ \\
\hline Heart-lung preparation & 15 & $\begin{array}{l}\text { Guanethidine ( } 10 \mathrm{mg} \text { in } \\
5 \mathrm{~min})\end{array}$ & $3 \mathrm{hr}$ & $0.59 \pm 0.072$ \\
\hline Heart-lung preparation & 20 & $\begin{array}{l}\text { Reserpine ( } 3 \mathrm{mg}) \\
\text { followed by } \\
\text { guanethidine } \\
(10 \mathrm{mg})\end{array}$ & $3 \mathrm{hr}$ & $0 \cdot 29 \pm 0.034$ \\
\hline Heart-lung preparation & 7 & $\begin{array}{l}\text { Noradrenaline }(480 \mu \mathrm{g} \\
\text { in } 30 \mathrm{~min})\end{array}$ & $3 \mathrm{hr}$ & $1 \cdot 60 \pm 0 \cdot 26$ \\
\hline $\begin{array}{l}\text { Heart-lung preparation } \\
\text { Heart-lung preparation } \\
\text { from reserpinized } \\
\text { dogs }\end{array}$ & $\begin{array}{l}17 \\
14\end{array}$ & $\begin{array}{l}\text { Noradrenaline }(480 \mu \mathrm{g} \\
\text { in } 30 \mathrm{~min})\end{array}$ & $\begin{array}{l}3 \mathrm{hr} \\
3 \mathrm{hr}\end{array}$ & $\begin{array}{l}0.85 \pm 0.08 \\
0.11 \pm 0.014\end{array}$ \\
\hline $\begin{array}{l}\text { Heart-lung preparation } \\
\text { from reserpinized } \\
\text { dogs }\end{array}$ & 6 & - & $3 \mathrm{hr}$ & 0 \\
\hline $\begin{array}{l}\text { Intact normal dogs, } \\
\text { pentobarbitone } \\
\text { anaesthesia }\end{array}$ & 17 & - & $\begin{array}{l}\text { Immediately after } \\
\text { anaesthesia }\end{array}$ & $1 \cdot 1 \pm 0 \cdot 094$ \\
\hline $\begin{array}{l}\text { Intact normal dogs, } \\
\text { chloroform anaes- } \\
\text { thesia and bleeding }\end{array}$ & 22 & - & $\begin{array}{l}\text { Immediately after } \\
\text { anaesthesia and } \\
\text { bleeding }\end{array}$ & $1.0 \pm 0.065$ \\
\hline
\end{tabular}

Table 1 and Fig. 5 summarize estimations of the noradrenaline content of atria under the various conditions of use of the heart-lung preparation and in the normal dog.

\section{DISCUSSION}

The idea that the positive chronotropic effects of reserpine and of guanethidine on the dog heart-lung preparation are due to liberation of noradrenaline from "stores" has received considerable support. Paasonen \& Krayer (1958) and Krayer et al. (1962) compared the amounts of noradrenaline released in $2 \mathrm{hr}$ by doses of reserpine and guanethidine which caused a maximal increase in heart rate. In five heart-lung preparations, each treated with $3 \mathrm{mg}$ of reserpine, the average noradrenaline content of the right atrium after 2 to $3 \mathrm{hr}$ was $0.31 \mu \mathrm{g} / \mathrm{g}$, or $26 \%$ of the average control value of $1.2 \mu \mathrm{g} / \mathrm{g}$ (standard deviation $=0.3, \mathrm{n}=7$ ) after the same length of time. The noradrenaline contents (mean \pm standard error) for the guanethidine experiments were: five controls, $1.64 \pm 0.15$; five heart-lung preparations after $10 \mathrm{mg}$ of guanethidine, $0.85 \pm 0.09$; five experiments after $30 \mathrm{mg}$ of guanethidine, $0.69 \pm 0.065$. Krayer et al. (1962) concluded that, since the amounts of noradrenaline released during the 2 -hr period by reserpine and by guanethidine were about the same, the difference between the maximal chronotropic effects of the two drugs cannot be explained by differences in the amounts of noradrenaline released. The difference between the intensities of the positive chronotropic effects of reserpine and guanethidine was attributed by these authors to a synergistic action of guanethidine and noradrenaline. 


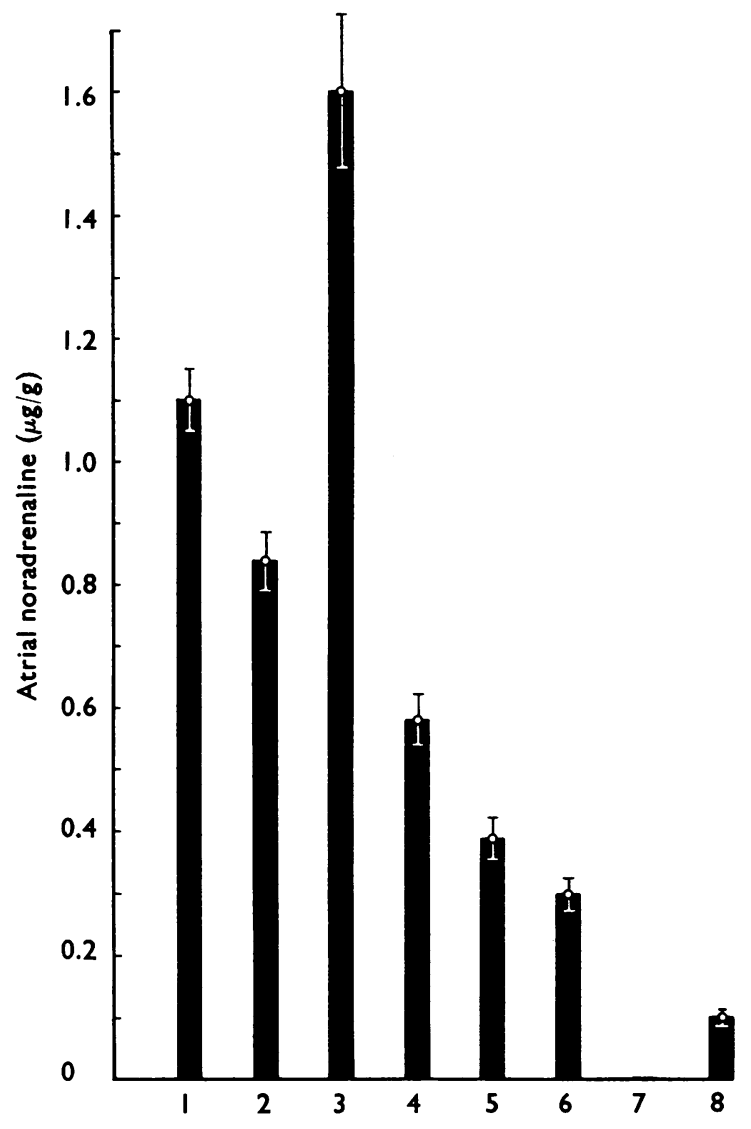

Fig. 5. Noradrenaline content of the right atrium of the dog under various conditions. The vertical bars indicate the standard errors of the means.

1. Dogs immediately after induction of anaesthesia with pentobarbitone (17 experiments). All subsequent estimates are from atria excised from heart-lung preparations $3 \mathrm{hr}$ after the start of the experiments.

2. No drug given (17 experiments).

3. After infusion of noradrenaline ( $480 \mu \mathrm{g}, 7$ experiments).

4. After guanethidine ( $10 \mathrm{mg}, 15$ experiments).

5. After reserpine ( $3 \mathrm{mg}, 15$ experiments).

6. After reserpine $(3 \mathrm{mg}$ ) followed by guanethidine ( $10 \mathrm{mg}, 20$ experiments).

7. After previous treatment with reserpine (6 experiments).

8. After noradrenaline infusion into dogs previously treated with reserpine $(480 \mu \mathrm{g}, 14$ experiments).

The results of Krayer et al. (1962) suggest that the mechanism of release of noradrenaline both by guanethidine and by reserpine is the same, and that both drugs probably act on the same store. Our results, however, seem to point to a more complicated picture. Fig. 1 shows that, when guanethidine was administered after the chronotropic effect of reserpine had completely subsided, the ascending limb of the curve was nearly identical to that obtained without prior treatment with reserpine, a finding not compatible with the idea that reserpine and guanethidine 
act by the same mechanism. The concept that they act on two different stores is more attractive to us. The descending limb of the curve for guanethidine after treatment with reserpine is steeper than that for guanethidine alone. The area under the curve for guanethidine given alone is almost double that for guanethidine after reserpine, and approximately equal to the total area under the reserpine and guanethidine curve. From this result one might be tempted to conclude that guanethidine liberates more noradrenaline than does reserpine. However, Fig. 5 shows that the opposite applies. Our results are in harmony with the interpretation of Krayer et al. (1962) that the more intensive chronotropic action of guanethidine compared to reserpine is not due to the release of a greater amount of noradrenaline by guanethidine. Combined treatment with both guanethidine and reserpine liberates more noradrenaline than does treatment with either alone. Caution is necessary when interpreting these results in a quantitative rather than a qualitative manner. There are considerable variations in the noradrenaline content of hearts and, since an animal cannot serve as its own control, it is difficult to detect small changes in noradrenaline content with any precision even with the large number of experiments we have done. Paasonen \& Krayer (1958) report a value of 1.2 (standard deviation, $0.3) \mu \mathrm{g} / \mathrm{g}$ for the atrial noradrenaline content of heart-lung preparations after the lapse of 2 to $3 \mathrm{hr}$, compared with 0.76 (standard deviation, 0.21$) \mu \mathrm{g} / \mathrm{g}$ for hearts of intact large animals anaesthetized with pentobarbitone. We have obtained opposite results using a larger number of animals : 0.85 (standard error, 0.08$) \mu \mathrm{g} / \mathrm{g}$ for atria from heart-lung preparations and 1.1 (standard error, 0.09$) \mu \mathrm{g} / \mathrm{g}$ for atria from intact animals anaesthetized with pentobarbitone. In a series of twenty-two blood donor dogs anaesthetized with chloroform, the atria contained 1.0 (standard error, 0.065) $\mu \mathrm{g} / \mathrm{g}$. . Krayer et al. (1962) reported 1.64 (standard error, 0.15) $\mu \mathrm{g} / \mathrm{g}$ for heart-lung preparations after a lapse of 2 to $3 \mathrm{hr}$. The variations in the noradrenaline content of normal rat hearts are also great. Potter, Axelrod \& Kopin (1962) report a value of 1.2 (standard error, 0.16$) \mu \mathrm{g} / \mathrm{g}$ for one group of rats and 0.87 (standard error, $0.03) \mu \mathrm{g} / \mathrm{g}$ and 0.89 (standard error, 0.04) $\mu \mathrm{g} / \mathrm{g}$ for another. Krayer et al. (1962) give values of 0.43 (standard deviation, 0.054$) \mu \mathrm{g} / \mathrm{g}$ and 0.49 (standard deviation, $0.14) \mu \mathrm{g} / \mathrm{g}$ for their rats, while Muscholl (1961) found 0.59 (standard error, 0.02) $\mu \mathrm{g} / \mathrm{g}$ for his rats.

Treatment of the heart-lung preparation with noradrenaline $(480 \mu \mathrm{g})$ increased the noradrenaline content of the right atrium. This confirmed results of previous workers with intact animals and with isolated tissues (see Peart, 1962 ; Muscholl, 1961). It would appear from Figs. 2 and 3, however, that this extra noradrenaline is not liberated either by reserpine or by guanethidine, since the curves for reserpine and guanethidine after treatment with noradrenaline did not differ from those obtained when no noradrenaline was infused. We may well be dealing here with yet another noradrenaline store. If a heart-lung preparation from a dog treated with reserpine (which dog contains no detectable amounts of noradrenaline) is infused with noradrenaline $(480 \mu \mathrm{g})$, the atrium also takes up noradrenaline, although the amount is small $(0.11 \mu \mathrm{g} / \mathrm{g})$. We have extracted, in thirteen out of fourteen experiments, clearly detected amounts of noradrenaline and consider this change more marked than, for example, the difference between the noradrenaline content after combined treatment with reserpine and guanethidine and that after reserpine alone 
(Fig. 5). Treatment of the repleted preparation with guanethidine yielded a curve similar in shape to that obtained with administration of guanethidine after reserpine (Fig. 1) except for a slightly smaller maximum. Muscholl (1960) and Furchgott \& Kirpekar (1961) noted only the effect of noradrenaline repletion in rat and guinea-pig atria before treatment of the animals with reserpine, but could detect no increase in noradrenaline content. On the other hand, Crout et al. (1962) found an increase in noradrenaline after repletion of guinea-pig isolated atria, although it was less than $2 \%$ of the normal noradrenaline content and much smaller than the increase we noted for the dog.

On the basis of these findings we have suggested that two stores of noradrenaline exist, " one situated adjacent to the effector cells, e.g., the store filled by the repletion experiment and another store where released noradrenaline would have to cover a longer distance, perhaps through the blood stream, to reach its target" (Fawaz, 1963). We consider that the first (smaller) store is probably depleted by guanethidine and the second store by reserpine, although these two drugs can deplete both stores if given sufficient time to act. A third store can be adduced to account for uptake of noradrenaline infused into a preparation not treated with reserpine. Potter et al. (1962) have experimental evidence with radioactive noradrenaline which supports the hypothesis of the existence of these cardiac noradrenaline stores. Crout et al. (1962) also report results dealing with the action of tyramine on partially depleted guinea-pig atria which they interpret as consistent with the view that two noradrenaline compartments exist in the heart.

We have found that the average initial heart rates in two series of nine and fourteen preparations after treatment with reserpine were 139 and 136 beats/min respectively, and thus not very different from rates in normal preparations. This confirms earlier results of Fawaz (1961). It would appear then that the noradrenaline stores as such do not affect the activity of the cardiac pace-maker, at least in the dog. A related question arises: is noradrenaline "used up" as a heart-lung preparation runs for $3 \mathrm{hr}$ ? Our results indicate that intact dogs anaesthetized with pentobarbitone have a slightly higher atrial noradrenaline level than do heart-lung preparations maintained for $3 \mathrm{hr}$, although Paasonen \& Krayer (1958) obtained opposite results. It is unlikely that this decrease in noradrenaline content was due to hypoxia since the blood was always well oxygenated. Furthermore, pieces of the atria, incubated at $37^{\circ} \mathrm{C}$ in air for $1 \mathrm{hr}$, showed no loss of noradrenaline content.

We wish to thank the Sterling-Winthrop Research Institute, Rensselaer, N.Y., for their gift of noradrenaline bitartrate (Levophed) and Ciba, Basle, Switzerland, for generous supplies of reserpine base and guanethidine (Ismelin). This work was supported by a grant from the American Heart Association.

\section{REFERENCES}

Bertler, A., Carlsson, A. \& Rosengren, E. (1956). Release by reserpine of catechol amines from rabbit's hearts. Naturwissenschaften, 43, 521 .

BURN, J. H. \& RAND, M. J. (1958). The action of sympathomimetic amines in animals treated with reserpine. J. Physiol. (Lond.), 144, 314-336.

Carlsson, A., Rosengren, E., Bertler, A. \& Nilsson, J. (1957). In Psychotropic Drugs, ed. GaratTinI, S. \& Ghetti, V., pp. 363-372. Amsterdam: Elsevier.

Crout, J. A., Muskus, A. J. \& TRENDElenburg, U. (1962). Effect of tyramine on isolated guineapig atria in relation to their noradrenaline stores. Brit. J. Pharmacol., 18, 600-611. 
vON EULER, U. S. (1957). Noradrenaline, p. 64. Springfield: C. C. Thomas.

FAWAZ, G. (1961). The effect of mephentermine on isolated dog hearts, normal and pretreated with reserpine. Brit. J. Pharmacol., 16, 309-314.

Fawaz, G. (1963). Ann. Rev. Pharmacol., 3, in press.

FAwaz, G. \& Tutuni, B. (1957). The mechanism of dinitrophenol heart failure. Brit. J. Pharmacol., 12, 273-278.

FURCHGOTT, R. F. \& KIRPEKAR, S. M. (1961). Competition between $\beta$-haloalkyl-amines and norepinephrine for sites in cardiac muscle. Biochem. Pharmacol., 8, 11 .

GAFFNEY, T. E. (1961). The effect of guanethidine and bretylium on the dog heart-lung preparation. Circulat. Res., 9, 83-88.

Jantzen, E. \& Schmalfuss, H. (1929). Protective evaporation at low temperature. Chem. Fabrik., 2, 388-391.

Krayer, O., Alper, M. H. \& PaAsonen, M. K. (1962). The action of guanethidine and reserpine upon the isolated mammalian heart. J. Pharmacol. exp. Ther., 135, 164-173.

KRAYER, O. \& FUENTES, J. (1958). Changes of heart rate caused by direct cardiac action of reserpine. J. Pharmacol. exp. Ther., 123, 145-152.

Muscholl, E. (1960). Die Hemmung der Noradrenalin-Aufnahme des Herzens durch Reserpin und die Wirkung von Tyramin. Naunyn-Schmiedeberg's Arch. exp. Path. Pharmak., 240, 234-241.

MusChOLL, E. (1961). Effect of cocaine and related drugs on the uptake of noradrenaline by heart and spleen. Brit. J. Pharmacol., 16, 352-359.

PAASONEN, M. K.\& KRAYER, O. (1958). The release of norepinephrine from the mammalian heart by reserpine. J. Pharmacol. exp. Ther., 123, 153-160.

Peart, W. S. (1962). Drugs affecting the blood pressure and vasomotor tone. Ann. Rev. Pharmacol., 2,252-256.

POTTER, L. T., AXELrod, J. \& Kopin, I. J. (1962). Differential binding and release of norepinephrine and tachyphylaxis. Biochem. Pharmacol., 11, 254-256. 